Lancet (1974). Partially treated meningitis, 1, 55-56.

Smith, D. H., Peter, G., Ingram, D. L., Harding, A. L., and Anderson, P. (1973). Responses of children immunized with the capsular polysaccharide of Hemophilus influenzae, type b. Pediatrics, 52, 637-644.

\section{J. GoldaCRE}

Department of Social and Community Medicine, University of Oxford, 8 Keble Road, Oxford OXI $3 Q N$.

\section{Neonatal vaccination with 'universal strength' $B C G$ vaccine}

In April 1975, the intradermal BCG vaccine used in the UK was changed to 'universal strength', which is approximately twice the strength of the old. This report concerns the first results with 'universal strength' BCG in newborn infants in the UK and will later report the tuberculin response over a oneyear period. Useful information on the acceptability of the vaccine has already been obtained.

\section{Method}

Consent was sought from mothers of children born in the Fazakerley Hospital, Liverpool, to have their infant vaccinated with BCG, and vaccination generally took place within the first few days of life. $0.05 \mathrm{ml}$ universal strength BCG vaccine $\left(12.4 \times 10^{6}\right.$ viable units $/ \mathrm{ml}$ ) was given by intradermal injection with syringe and needle into the upper arm. The infants were seen again at 2 months when the BCG vaccination lesion was examined and measured. A Mantoux test using 5 tuberculin units (Tu) of PPD-S (0.0001 mg PPD-S, CDC, Atlanta, Ga., USA) was performed. This tuberculin test will be repeated 1 year after vaccination.

\section{Results}

Of 219 children vaccinated, 159 had their BCG lesions measured. The Fig. shows the distribution of lesion diameters, the mean diameter being $5.2 \mathrm{~mm}$ 2 months after vaccination. As shown in the Table, about a third of the lesions discharged, lasting only 2 to 3 days in most. In 2 infants deep ulcers developed which healed without treatment in 2 and 3 days. The Table also shows that 15 of the 146 infants Mantoux-tested had tuberculin reaction diameters $<5 \mathrm{~mm}$, giving a conversion rate (Mantoux reaction $\geqslant 5 \mathrm{~mm}$ diameter induration) of $90 \cdot 3 \%$.

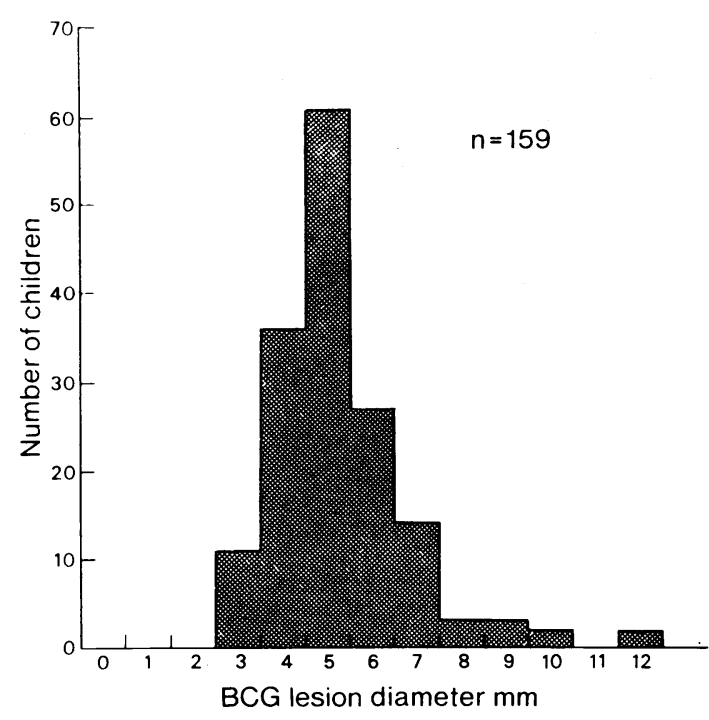

Fig. BCG lesions in 159 neonates.

Table Details of BCG vaccination and Mantoux test

\begin{tabular}{lc}
\hline Total no. vaccinated & 219 \\
No. BCG lesions examined & 159 \\
Mean diameter of BCG lesion & $5 \cdot 2 \mathrm{~mm}$ \\
No. of BCG lesions with discharge & 52 \\
Mean no. of days with discharge & $2-3$ \\
No. with ulcers & 2 \\
No. Mantoux tested & 146 \\
No. with lesions $<5 \mathrm{~mm}$ induration & 15 \\
Conversion rate $\geqslant(5 \mathrm{~mm}$ diameter $)$ & $90 \cdot 3 \%$ \\
\hline
\end{tabular}

\section{Discussion}

The results indicate that the universal strength BCG vaccine was well tolerated by newborn infants. The mean BCG lesion diameter was fairly small and together with the low incidence of ulcers indicates a very acceptable response to the vaccine. This confirmed previous findings in schoolchildren using BCG of similar strength (Brindle et al., 1972).

Although 15 infants appeared to be tuberculin negative 2 months after vaccination, this may be due to the low dose of PPD used. Previous work (Griffiths and Gaisford, 1956) suggests that a larger dose of PPD is required to elicit a tuberculin response in infants than in adolescent children. A dose of 100 Tu of Weybridge PPD has been used in infants with success, but 5 Tu was chosen to avoid severe reactions which might have occurred. A conversion rate of over $90 \%$ is still considered to be a satisfactory 'take'. 


\section{Summary}

'Universal strength' BCG vaccine was given to 219 neonates and 2 months later 159 infants were Mantoux-tested with $5 \mathrm{Tu}$ PPD-S and their BCG scars measured. The results showed a satisfactory conversion rate of over $90 \%$. Though $30 \%$ of the lesions discharged, this only lasted for a few days and the vaccine was well tolerated and acceptable for use in neonates.

\section{References}

Brindle, T. W., Griffiths, M. I., Holme, T., Stalker, R., Burland, W. L., Coates, G. A., and Muggleton, P. W. (1972). Trial to compare U.K. strength BCG vaccine with vaccine of double the moist weight content. Tubercle, 53, 106-110.

Griffiths, M. I., and Gaisford, W. (1956). Freeze-dried BCG. Vaccination of newborn infants with a British vaccine. British Medical Journal, 2, 565-568.

\section{B. HeYworth and BRenda M. Mullinger} Liverpool School of Tropical Medicine, and Clinical Division, Glaxo Research Ltd., Greenford, Middlesex.

Correspondence to Dr. B. Heyworth, Department of Tropical Paediatrics and Child Health, Liverpool School of Tropical Medicine, Pembroke Place, Liverpool L3 5QA.

\section{Primary hyperparathyroidism in a child}

\section{Use of jugular venous catheterization in diagnosis}

Primary hyperparathyroidism is rare in childhood. Less than 50 cases have been reported in children under 16 years of age. The majority have been due to chief cell adenomata and most have presented with bone pain and fractures. About $20 \%$ have presented with renal involvement (Nolan et al., 1960; Ahuja and Rao, 1973). With the development of immunoradiometric assays for parathyroid hormone (PTH), a new approach is possible to the diagnosis of parathyroid disease. In recent years this assay has been used to measure selective catheter samples from neck veins in adults to identify the site of the lesion before surgery, thus simplifying the surgical approach (Davies et al., 1973; Eisenberg et al., 1974). We report the use of this technique in the case of a 10-year-old boy with a parathyroid tumour.

\section{Case report}

The patient presented at the age of 10 with renal colic. Shortly afterwards ureteric and pelvic stones, which proved to be calcium oxalate stones, were removed surgically. Subsequently he had some mild polyuria and polydypsia and vague malaise and lethargy but no other specific symptoms. A random serum $\mathrm{Ca}$ was $14 \mathrm{mg} / 100 \mathrm{ml}(3.5 \mathrm{mmol} / \mathrm{l})$, and he was admitted for investigation.

His fasting $\mathrm{Ca}$ ranged from $11 \cdot 6$ to $13 \cdot 2 \mathrm{mg} / \mathrm{ml}$ $(2 \cdot 9-3 \cdot 3 \mathrm{mmol} / \mathrm{l})$. There was no radiological evidence of metabolic bone disease. After 14 hours' fluid deprivation maximal urine osmolality was $468 \mathrm{mOsm} / \mathrm{kg}$. PTH was measured by immunoradiometric assay, using the method of Addison et al. (1971). A fasting PTH was $1.0 \mathrm{ng} / \mathrm{ml}$ (normal $0 \cdot 1-0.9 \mathrm{ng} / \mathrm{ml}$ ).

In view of this borderline result and the suggestive clinical situation, jugular venous catheterization was performed. Under general anaesthesia a catheter was introduced into the femoral vein and advanced through the inferior vena cava and right atrium to the superior vena cava. Selective samples of blood were withdrawn in the superior vena cava, the right brachiocephalic and left brachiocephalic veins, the major thyroidal venous plexus on the right side and high and low left internal jugular sites. A venogram of the neck did not show any plexus suggestive of a tumour.

The samples thus obtained were immediately separated and frozen for later assay for PTH. The PTH levels at the various sample sites (Fig.) show a markedly raised PTH level in relationship to the common inferior thyroidal vein, thus suggesting the presence of a PTH-producing tumour.

At exploration of the neck a $1 \mathrm{~cm} \times 0.5 \mathrm{~cm}$. adenoma was found occupying the left inferior parathyroid, and was removed. The other three parathyroids were visualized and were of normal size. Histological examination of the resected tumour showed a chief cell adenoma within a normal parathyroid gland.

Apart from some minor neuromuscular excitability, the postoperative period was unremarkable. A repeat serum PTH 2 weeks postoperatively was $0.35 \mathrm{ng} / \mathrm{ml}$ and serum $\mathrm{Ca} 10 \cdot 1 \mathrm{mg} / 100 \mathrm{ml}(2.5$ $\mathrm{mmol} / \mathrm{l})$. There was no residual renal damage.

\section{Discussion}

This case shows the importance of serum PTH measurement in the diagnosis of parathyroid adenomata. In this age group there are relatively few causes of raised serum $\mathrm{Ca}$. While hyperparathyroidism was clinically suspected the problems associated with parathyroid exploration necessitated more sophisticated diagnostic techniques.

The serum PTH was only marginally raised. In 